\title{
DIFERENTES ABORDAGENS ANALÍTICAS PARA ESTUDOS DE MERCADOS DA PECUÁRIA
}

\author{
Alessandra Matte
}

\begin{abstract}
RESUMO
Diante da multiplicidade de formas em que os mercados podem estar organizados, este artigo tem por objetivo apresentar de forma sistematizada diferentes abordagens utilizadas para compreender as dinâmicas e o funcionamento dos mercados agropecuários, reconhecendo as contribuições das distintas escolas, como também algumas de suas fragilidades. Assim, foram selecionadas escolas e abordagens que pudessem ser interessantes para estudo mais específico de mercados pecuários no Sul do Brasil, de modo que fossem perspectivas que levassem em consideração aspectos sociais e econômicos. As constatações apresentadas nos põem diante da evidência de que aspectos econômicos, sociais e culturais compõem os elementos que orientam as trocas, e que distintas abordagens podem apontar para maneiras diferenciadas de entendê-las. Em síntese, essa revisão permitiu optar pelo uso da Teoria das Convenções, mostrando-se apropriada a considerar a diversidade de formas de mercados, não apenas entre organizações, mas dentro de uma organização. Assim, as convenções representam a convergência por trás da ação nos mercados, assinalando que há princípios e valorações comuns entre os atores, constituídos por referências em comum que norteiam essas interpretações.
\end{abstract}

Palavras-chave: comercialização, economia, sociologia.

\section{DIFFERENT ANALYTICAL APPROACHES FOR STUDIES OF LIVESTOCK MARKETS}

\begin{abstract}
Given the multiplicity of ways in which markets can be organized, this article aims to present in a systematic way different approaches used to understand the dynamics and the functioning of agricultural markets, recognizing the contributions of different schools, as well as some of their weaknesses. Thus, we selected schools and approaches that could be interesting for a more specific study of livestock markets in the South of Brazil, so that they could be perspectives that take into account social and economic aspects. The findings put us in the face of the evidence that economic, social and cultural aspects compose the elements that guide the exchanges, and that different approaches can point to different ways of understanding them. In summary, this review allowed us to opt for the use of Conventions Theory, and it is appropriate to consider the diversity of market forms, not only between organizations, but within an organization. Thus, the conventions represent the convergence behind the action in
\end{abstract}

1 Graduada em Zootecnia (UFSM). Mestrado em Desenvolvimento Rural (UFRGS). Doutorado em Desenvolvimento Rural (UFRGS). Professora Adjunta na Universidade Tecnológica Federal do Paraná (UTFPR), Campus Santa Helena. E-mail: alessandramatte@yahoo.com.br; amatte@utfpr.edu.br 
the markets, noting that there are common principles and values among the actors, constituted by common references that guide these interpretations.

Keywords: commercialization, economy, sociology.

\section{INTRODUÇÃO}

O entendimento sobre o que são mercados, do ponto de vista do senso comum, consiste em um espaço físico delimitado ocupado por indivíduos, um local ou lugar concreto em que ocorrem atividades comerciais, negociações, trocas e interações de todos os tipos, formas e produtos. Por outro lado, também pode ser entendido enquanto um destino para onde a mercadoria ou produção é enviada, até mesmo visto enquanto uma abstração - pass par tout -, desconhecido e impessoal, mas também real e concreto, uma vez que faz parte do cotidiano da sociedade por meio do mercado de capitais, de produtos, de mão de obra, entre outros.

Por outro lado, em meio aos estudos acadêmicos, sua compreensão também varia, tendendo a ser visto como um mecanismo interpessoal e que, na verdade, consiste em "[...] uma arena que confere às coisas o caráter de mercadoria em determinados momentos de sua vida social" (CONTERATO et al., 2011 , p. 72), de maneira que são caracterizados como um ambiente extremamente incerto e hostil, que necessita da construção de coalizões que sejam capazes, de alguma forma, de orientar as ações nesse espaço. Portanto, os mercados não são resultado da ligação de atores com o mesmo interesse, mas o produto de convenções, de representações socialmente compartilhadas sobre o mundo (NIEDERLE, 2013). Ou seja, são um conjunto de convenções constituídas pelos atores sociais por meio de especulações, de julgamentos e de justificativas, que delimitam o deslocamento e movimentação dos atores por diferentes espaços (THEVENOT, 1989; 2001; BOLTANSKI; THÉVENOT, 1991). Dessa maneira, a descrição de qualquer mercado deve envolver a identificação das mediações sociais e das formas de articulação que dão vida a essa estrutura, a fim de analisar o modo como os atores resolvem problemas de coordenação, na medida em que se torna necessário olhar para além das trocas ${ }^{2}$ realizadas, contemplando também as formas como os seus membros regulam e politizam essas trocas.

De alguma maneira, não se trata de um processo uniforme e acabado que orienta e transforma por completo a vida dos agricultores, mas sim um processo amplo e diverso, em que a complexa interseção de fatores temporais, culturais e sociais faz com que algumas coisas transitem no estado de mercadoria (PLOEG, 1993; LONG, 2007; APPADURAI, 2008). Desse modo, a inserção das formas familiares de produção na sociedade mais ampla é integral à medida que as categorias sociais que a compõem procuram garantir espaços de manobra para assegurar sua sobrevivência e, sobretudo, tornarem-se mais fortalecidas. Para isso, os desafios da agricultura familiar consistem em alcançar novos níveis de qualidade e novas escalas de produção, desenvolvendo principalmente iniciativas autônomas que favoreçam as formas tradicionais de intermediação dos mercados (WILKINSON, 2008).

${ }^{2}$ Sobre isso, é assumido por Sabourin (2006; 2009) que existem sociedades de trocas que não são mercantis, em que as práticas de reciprocidade e da dádiva entre comunidades camponesas geram formas de aliança consolidadas que permitem multiplicar as relações interpessoais. Por outro lado, também existem sociedades em que as trocas são mercantis, isso porque os mercados necessitam de trocas. Entretanto, nem sempre as trocas são necessariamente mercantis. Ou seja, tomadas como um conjunto de interações sociais, as trocas mercantis devem ser examinadas em um contexto mais vasto para, assim, lhe ser atribuído um sentido real (GARCIA-PARPET, 2009). 
Diante da multiplicidade de formas em que os mercados podem ser organizados, este artigo tem por objetivo sistematizar as diferentes abordagens utilizadas para compreender as dinâmicas e o funcionamento dos mercados, reconhecendo as contribuições das distintas escolas, como também apontar algumas fragilidades. Assim, o leitor interessado em realizar um estudo sobre a temática dos mercados, poderá ter um panorama geral por meio do texto, e, associado ao contexto empírico que defini sua problemática, poderá decidir sua escolha teórica com maior convicção.

\section{MERCADOS AGROPECUÁRIOS: DIFERENTES ABORDAGENS ANALÍTICAS PARA ESTUDOS RURAIS}

A direção que guia a sociedade para um modelo que, com frequência e intensidade cada vez maiores, põe toda e qualquer coisa à venda preocupa por seus consequentes índices de desigualdade, principalmente para aqueles que dispõem de poucos recursos (SANDEL, 2014). Acontece que a mercantilização das coisas acentuou e aguçou a desigualdade e enfatizou a importância do dinheiro ao longo do tempo (APPADURAI, 2008; SANDEL, 2014). Quando um bem passa a ser comercializado, este se transforma em mercadoria, perdendo sua identidade e vindo a ser considerado um instrumento de lucro e uso. A diferença, contudo, está na maneira como são atribuídos valores às coisas. Por exemplo, para acionistas de um grande frigorífico, a orientação segue o objetivo de obter o lucro, mas, para um pecuarista familiar, o lucro é apenas um dentre os fatores que determinam a comercialização de seu produto - e nem sempre é o principal. As escolhas entre os canais de comercialização não seguem as mesmas lógicas, e é isso que precisa ser melhor compreendido. Outro exemplo ilustrativo dessa situação é o caso da terra na pecuária familiar, que, geralmente, advém da herança, ou seja, fruto de relações não mercantis (MATTE, 2013). Trata-se de um conjunto de elementos que não são inteiramente mercantilizados, mas explicam, entretanto, a existência de formas não mercantis dentro de sociedades mercantilizadas. Cabe mencionar que a sociedade de mercado não foi um processo espontâneo. O que deu à luz a essa forma está muito mais relacionado a uma "intervenção política consciente", em uma direção específica (OZVEREN, 2007, p. 789). Por isso, serão resgatados subsídios de diferentes escolas do pensamento sobre os mercados no intuito de reconhecer sua atualidade $e$ contribuições, especificamente para compreender mercados da pecuária.

A escola clássica, que tem como principal representante Adam Smith, compreende o mercado como uma "mão invisível" que organiza o equilíbrio entre quem têm a oferta (produto para venda) e a demanda. Para Smith, em sua obra "Uma investigação sobre a natureza e as causas da riqueza das nações", dedicada a explicar a natureza do sistema econômico, as mudanças pelo qual a economia passava no século XVIII e os novos caminhos diante da Revolução Industrial inglesa que engatinhava, permite que 0 autor constate que o mercado consiste de um dispositivo coletivo por meio do qual a sociedade aloca a riqueza segundo o princípio do mérito e da competência individual. A contribuição dessa escola é que o valor - e, portanto, o preço dos bens e serviços - é determinado pelas condições da oferta e da procura. Conforme evidenciado por Ellis (1988, p. 10), no modelo de concorrência perfeita não pode existir nenhuma coerção, dominação ou exercício do poder econômico por parte de alguns agentes econômicos sobre os outros. Contudo, a discussão acerca da concorrência pura e perfeita pode até ser explicativa, mas marginaliza os aspectos sociais, interpretados como um obstáculo ou variável residual. Essa característica acaba resultando em um distanciamento entre o que é apresentado nos "modelos", entre o que de fato é observado na realidade. 
Cabe mencionar que o desenvolvimento do capitalismo moderno pode ser visto como um processo de expansão dos mercados como mecanismos para a produção e distribuição de bens e serviços, mas essa dramática expansão não significa que os mercados são os únicos instrumentos que regulam os processos econômicos em economias capitalistas (BECKERT, 2007; 2009). A radicalização do capitalismo pretende a existência da economia pura, de uma economia per se (por si só), justificando-se e existindo para o lucro. Isso torna uma sociedade altamente instável, gerando o risco da anomia social e da desintegração das sociedades, pois nenhuma sociedade poderá se sustentar dessa forma por muito tempo.

Na perspectiva de Marx (1994), ao contrário da escola clássica, o mercado é profano, uma vez que mescla características de ser mágico, mas também obscuro. Para o autor, o mercado é um fetiche, consiste no espaço em que o trabalho "vivo" se transubstancia, ou seja, perde substância real e passa a ser uma substância imaterial, como em uma quantidade de papel (dinheiro) ou no cartão de crédito. O mercado "desencarna" as coisas reais, posto que as mercadorias recebem a condição de fantasmas, tornando-se despersonalizadas. O mercado é o palco da alienação em que desfilam mercadorias sem identidade, configurando o cenário do "fetichismo" da mercadoria (MARX, 1994). Em crítica à visão marxista de mercadorias, Appadurai (2008) argumenta que nem todas as coisas se despersonalizam, e uma das estratégias de inserção da agricultura familiar em sociedades mercantilizadas é justamente recuperar a identidade do alimento e de quem o produz, por meio de localização, de identificação, de certificação e do contato pessoal produtorconsumidor. Nesse sentido, os mercados continuam existindo enquanto um espaço de troca e de interação social.

Soma-se ao portfólio de teorias para a análise dos mercados a Nova Economia Institucional (NEI), derivada da economia institucional ou institucionalismo - que basicamente contribuiu com a compreensão do papel das instituições no comportamento econômico -, propõe a ideia de contratos como um redutor do oportunismo e dos custos de transação como formas de resolver os problemas causados pelas falhas de mercado (COASE, 1937; NORTH, 1990). Entre os autores que apresentam importante contribuição sobre a NEI, encontra-se o estadunidense Oliver Williamson (1991; 1993), com avanços nos estudos da Economia dos Custos de Transação e Teoria da Firma. Suas ideias, que Ihe consagraram o Nobel em Ciências Econômicas, em 2009, contribuem na medida em que permite constatar que não há conhecimento integral sobre o ambiente decisório, e modo que as ações e decisões nos mercados buscam soluções eficientes, mesmo com informações limitadas. A visão institucional, assim como a neoclássica tratada na sequência, pode ser interessante para compreender algumas formas específicas de mercados. No caso dos mercados de grãos, a oferta e demanda podem influenciar nessa regulação, portanto, a teoria neoclássica pode ser útil nesses estudos (STEINBERG, 2006; CORONEL et al., 2008; SOUZA, 2014). Nas produções de suínos, leite, aves e na fumicultura, seus mercados podem ser estudados a partir das relações contratuais, ancorados pela Nova Economia Institucional (ZYLBERSZTAJN, 1995; SILVA, 2002; OLIVEIRA, 2011; FRANÇOIS, 2013; SILVA, 2015). Contudo, apesar de suas contribuições na observação e análise dos custos de transação, principalmente no reconhecimento de que estes não são neutros, essa escola apresenta uma fragilidade em sua lógica, visto que o contrato é apenas uma superfície social de acordos morais muito mais amplos. Ou seja, é necessário um acordo entre as partes de que o contrato será um instrumento válido e considerado importante. Para alguns pode se tornar efetivo, para outros, o compromisso assumido é firmado pela palavra ou no "fio de bigode". 
Uma quarta contribuição vem da escola neoclássica, que compreende o mercado como o espaço onde oferta e demanda se encontram, onde atores estabelecem os preços que regulam os níveis ótimos de apropriação relativa. Vale reconhecer que em meio à escola neoclássica, diferentes correntes de estudos derivam dessa importante escola. Contudo, em vista do reduzido espaço para aprofundamento e de uma escolha por identificar elementos suficientes para apontar pistas de diferentes abordagens que permitam estudar os mais variados mercados, optou-se por não aprofundar sobre esse debate. A quem interessar estudos por meio da escola neoclássica, há vasta variedade de correntes, entre as quais mencionaria as discussões que abarbam Estrutura, Conduta e Desempenho (ECD), em que mais informações podem ser encontradas na obra da professora Ana Lucia Gonçalves da Silva (2010). Assim, reconheço as contribuições e a pertinência da escola neoclássica, mas em vista do interesse em compreender abordagens que levem em consideração as relações sociais e culturais de forma mais aprofundada, optou-se por não realizar aprofundamento maior nos avanços neoclássico, sem tirar-lhes legitimidade.

A Teoria Neoclássica é assentada na ideia de que os mercados são perfeitos por natureza, por isso, se algo falhar, é porque alguém falhou, mas não a teoria. A compressão sobre mercados perfeitos pressupõe que cada ator toma suas decisões para maximizar seus interesses, e, por meio da maximização de interesses individuais, levar-se-á ao equilíbrio dos interesses coletivos (ROSSETTI, 1980). Assim, parte-se do pressuposto da existência de um atomismo, em que cada indivíduo - como um átomo - satisfaz suas demandas e interesses pessoais. Entretanto, essa premissa passa a ser criticada recentemente, principalmente por institucionalistas históricos, como Oliver Williamson $(1985 ; 1991)$ e outros. A crítica está alicerçada na constatação de que nem sempre os atores têm todas as informações disponíveis em mãos, por isso não há como saber de tudo, ou seja, existem falhas de mercado. A partir da aceitação da existência de falhas de mercado por parte da teoria econômica, essa passa a reconhecer o papel do Estado, atribuindo-Ihe a função de mecanismo de correção das falhas de mercado.

Doravante o reconhecimento das falhas de mercado, perspectivas que incorporam elementos sociais na construção dos mercados passam a ganhar espaço e legitimidade, dentre elas o aporte das relações sociais e de confiança propostas por George Akerlof (1970); a ideia de reciprocidade, de instituições e de embeddedness, de Karl Polanyi (1976; 1980); e a perspectiva de redes de interação social, juntamente com as contribuições da Nova Sociologia Econômica. Adicionalmente a essas, também cabe destacar as proposições de mercados de cadeias curtas, de Terry Marsden e colaboradores, de mercados aninhados, de Jan Douwe Van Der Ploeg e outros, e de relocalização, de Maria Fonte (2008) principalmente. Por fim, as contribuições da Teoria das Convenções, preenchem espaços não ocupados pelas demais teorias. Em essência, a questão central de todas essas teorias e abordagens é a ideia de que o mercado não é só uma questão da economia, como uma dimensão separada do social e do cultural.

O ganhador do Nobel de Economia em 2001, George Akerlof, marca sua trajetória acadêmica ao analisar o mercado dos lemóns (em tradução, limões), uma analogia à diferenciação de produtos pela qualidade, analisando o mercado de automóveis usados ou de qualidade duvidosa (AKERLOF, 1970). O autor busca entender por que existe um mercado de coisas usadas, questionando como é realizado o julgamento a respeito da "qualidade" para esses produtos. Akerlof (1970) constata que a base para o funcionamento desse mercado é a confiança e a informação, propondo que todos os mercados se organizam com algum grau de confiança, mesmo em espaços como o mercado de ações. De alguma forma, o autor procura realizar um ajuste à teoria das falhas de mercado ao afirmar que estas podem 
ser boas, pois os atores criam formas de resolver essas questões. Desse modo, ele reconhece que ocorrem comercializações mesmo com assimetria de informações, pois os mercados estão imersos em relações sociais e de confiança. EymardDuvernay (1989) mostrou que a existência de mercados de bens estáveis está ligada às convenções coletivas implícitas entre compradores e vendedores. Portanto, o mercado possui meios para fornecer informações para aqueles que delas necessitam.

Garcia-Parpet (2003), em seu texto sobre o mercado perfeito dos morangos, constata que o elemento central nessa forma de mercado é a informação que circula entre os envolvidos, com importante ação sobre o processo de tomada de decisão com relação ao preço. Conforme a autora, os preços são dados não pela concorrência, mas pelo tipo de informação que se obtém, tanto para compradores, como para vendedores. Esse caso evidencia a importância da construção de confiança e da circulação de informação nos mercados, despertando nossa atenção para o papel dessas ações para a construção de autonomia, principalmente de agricultores e pecuaristas familiares, suporte esse que pode ser encontrado na Teoria das Convenções. A partir disso, é possível observar que as políticas públicas têm um espaço importante a ocupar, mas é necessário compreender melhor como o Estado poderia facilitar a troca de informações, de forma que os agricultores pudessem tomar decisões mais bem instruídos. É preciso pensar algo que reconheça e valorize a construção de convenções, e não que se proponha a regular as interações sociais e a troca de informações.

Polanyi (1976) dizia que se as forças do mercado forem deixadas livres, tenderiam a provocar uma total e completa crise. Entretanto, deve-se considerar que o autor faz essa análise após duas guerras mundiais, as quais teriam sido provocadas pelo capitalismo. Nesse contexto, Polanyi afirma que o capitalismo funciona como uma espécie de "moinho satânico", como um moedor de carne, que transforma o homem, a terra e o dinheiro em suas mercadorias. É como reificar e anular o próprio ser humano.

Diante desse cenário, Polanyi (1976) se torna atual ao questionar a noção de que a economia de mercado foi mais "racional" ou mais eficiente do que outras formas de organização econômica baseadas em princípios diferentes. $O$ autor discute 0 contexto social de sociedades primitivas, tendo em mente a experiência da sociedade após duas guerras mundiais, admitindo que o capitalismo se desenvolve sem, no entanto, necessariamente eliminar as outras formas de interação social, estabelecendo uma visão completamente distinta da economia política marxista, especificamente.

O autor apresenta pistas importantes para estudar os mercados, não como propriedade do capitalismo, mas como mecanismo de interação social, porque, afinal de contas, mercados e trocas existem em sociedades não mercantilizadas e mercantilizadas (POLANYI, 1976; 1980). Seu argumento é justificado com base nas relações das sociedades primitivas, que também fazem trocas, entretanto não utilizavam um papel moeda para isso, não sendo uma relação de troca baseada na expropriação do trabalho. Polanyi (1976) fornece bases para entender a interação entre agricultores familiares e o capitalismo, apontando que os agricultores familiares realizam trocas, ou seja, trocam por papel moeda seus produtos, que entram na circulação de mercadorias, sendo comprados pelos consumidores. Contudo, isso não significa que os agricultores familiares participam de uma sociedade inteiramente mercantilizada. Isto é, apesar de empregar seus produtos na realização de trocas, os agricultores familiares também os empregam no domínio privado.

Assim, as sociedades nas quais Polanyi (1976) acredita são sociedades em que há instituições assentadas na troca e na reciprocidade, e instituições assentadas 
em mercados impessoais e autorregulados ${ }^{3}$, atribuindo um valor sociológico às transações. Ainda conforme o autor, a regulamentação do mercado passa a se dar pela sociedade, e não apenas pela economia, argumentando que a ação econômica nas sociedades tradicionais ficou totalmente enraizada na conduta social, enquanto a sociedade moderna caracteriza-se pelo fenômeno de desenraizamento (WILKINSON, 2008).

A partir disso, o autor examina atividades econômicas que sobreviveram na atual sociedade moderna, apontando a existência de três princípios de integração social, quais sejam: costumes de reciprocidade, formas de redistribuição, e intercâmbios (trocas não mercantis) (POLANYI, 1976). A reciprocidade é um princípio baseado em valores como comunitarismo, solidariedade, parentesco e cooperação, supondo um movimento entre pontos correlativos de agrupações simétricas. A redistribuição consiste em um movimento de apropriação em direção ao um centro e, posteriormente, de realocação a partir deste centro, estando baseada em princípios como coesão social, contratos, regras e redistribuição. As duas primeiras eram entendidas como atividades econômicas que promoviam a coesão social. Por intercâmbio, entendemos movimentos recíprocos como os que os atores realizam em um sistema de mercado. Alguns princípios tendem a se expandir, como o individualismo, a propriedade privada, a livre compra e venda, e a concorrência. Isso não significa que o "jeito" camponês de fazer trocas não sucumbe, mas se torna enfraquecido em uma sociedade altamente complexa. Polanyi sustentava que, sem essa economia informal, sem os inúmeros pequenos serviços prestados entre os membros de uma família, entre amigos e entre vizinhos, a sociedade não conseguiria sobreviver. O desenvolvimento desses diversos esforços cooperativos constitui uma tendência na sociedade, reconhecida pelo autor como contramovimento, destinada a criar modelos de desenvolvimento econômico alternativos, locais ou regionais. A exemplo disso, uma cooperativa e uma empresa privada são duas organizações capitalistas. Contudo, o que as diferencia é que a primeira está baseada em torno de princípios de centralidade, enquanto a outra é baseada no lucro, portanto, acionam os mecanismos de troca com interesses distintos.

Ao encontro dessa perspectiva, Wilkinson (2008) analisa os micros e pequenos empreendimentos agroindustriais e argumenta que esses mercados podem ser vistos como prolongamento de relações familiares, em que a confiabilidade do produto decorre da confiança no produtor, podendo dispensar garantias formais de qualidade. Nas palavras do autor, "parentesco, vizinhança, conhecimento pessoais e transações repetidas entre os mesmos atores afirmam reputações e consolidam lealdades, fazendo com que tais mercados se tornem relativamente imunes de pressões externas, sejam de ordem mercadológica ou reguladora" (WILKINSON, 2008, p. 94). Não se trata de limitações na competência dos agricultores familiares em produzir produtos de qualidade e em quantidade suficientes, mas trata-se, principalmente, da criação de regulamentações que pressupõem investimentos em instalações e equipamentos muitas vezes incompatíveis com as propriedades familiares. Essas ações caminham em direção a uma oligopolização, o que tem promovido a expansão de atividades clandestinas (WILKINSON, 2008).

Mais especificamente, no que tange ao debate em torno das redes sociais como formas de mercados, há uma polissemia em sua origem e por dentro do próprio debate. Segundo Scherer-Warren (2006), o ponto-chave está na utilização da noção

\footnotetext{
${ }^{3}$ Foi no século XIX que o fenômeno denominado de mercado autorregulado veio à tona, por meio da liberação do controle da sociedade dos inputs terra, trabalho e dinheiro. A partir dessa situação, as regulações se dão orientadas pelos mercados, a denominada "mão invisível". Entretanto, essa situação torna-se insustentável, resultando, por fim, no retorno da regulamentação do mercado pela sociedade.
} 
de redes como uma nova compreensão da morfologia social, baseada no princípio da informação ou da comunicação como um mecanismo e um espaço de interação social. O pressuposto básico da perspectiva de redes sociais é que a construção de novos mercados não ocorre em um vazio social: ela se dá por meio de relações sociais entre distintos atores que possuem algum vínculo ou proximidade (GRANOVETTER, 2009). Para isso, a abordagem de embededdness (enraizamento social) é retomada, tendo como pressuposto fundamental que redes sociais - construídas no parentesco ou amizade, confiança ou boa vontade - sustentam as relações econômicas e instituições. Assim, os fenômenos econômicos são explicados por meio de referências e variáveis sociológicas (LIE, 1997; GRANOVETTER, 2009; MIZRUCHI, 2009). O enraizamento enfatiza o papel das relações pessoais concretas e as redes (estruturas) dessas relações. Para Granovetter (2009), o homem sempre elaborou (em graus distintos) os seus cálculos econômicos a partir da sua inserção em redes sociais.

No que diz respeito aos mercados de cadeias curtas, Marsden et al. (2000) esclarecem que o termo "curto" não se refere à distância física que o alimento percorre, mas sim ao fato de o produto passar por poucas etapas até chegar ao consumidor, preservando, portanto, suas informações por meio de uma identificação própria ou da comunicação pessoal com o produtor. Para os autores, é isso que permite ao consumidor a "confiança de fazer conexões e associações com o lugar/espaço de produção, e, potencialmente, os valores das pessoas envolvidas e os métodos de produção utilizados". Uma das principais características das cadeias curtas é a capacidade destas em "re-socializar" ou "re-espacializar" um determinado alimento, permitindo ao consumidor atribuir-Ihe juízos de valor com base no seu próprio conhecimento, experiência ou imaginário percebido (MARSDEN et al., 2000; MARSDEN, 2004).

No Brasil, em resultados obtidos por Ferrari (2011), as cadeias curtas se caracterizam por enraizar práticas alimentares em relações ecossociais locais, criando novos espaços econômicos, conformando, por meio da produção e mercantilização de alimentos, uma relação de confiança entre produtores e consumidores. O autor ainda destaca que a emergência dessas cadeias curtas resulta de processos de proximidade, com significativa relação com a construção de redes por parte dos agricultores. As cadeias analisadas são caracterizadas, principalmente, pelas noções de relocalização, embeddedness e um turn ${ }^{4}$ para a qualidade.

Para Fonte (2008), a valorização do local como prática baseada no conhecimento das populações mobiliza as diversas formas de conhecimento incorporadas em atores rurais e não rurais. Conforme a autora, "relocalização de alimentos implica uma mobilização de conhecimentos" (FONTE, 2008, p. 211), no sentido de oposição ao homogêneo e em defesa do tradicional como um modo único e destoante do padronizado, preservando uma maneira de produzir e de consumir de uma população. Para Dupuis e Goodman (2005, p. 361), o localismo torna-se uma contra-hegemonia à tese da globalização, uma chamada à ação sob a alegação de que o "oponente ao poder global é o poder local". Em outras palavras, "se a dominação

\footnotetext{
${ }^{4}$ O termo "quality turn" ou "virada" da qualidade se apresenta como elemento propulsor de iniciativas contrárias às propostas homogeneizantes presente no mercado, evocando para o debate noções de confiança e embeddedness (enraizamento) (GOODMAN, 2003). Em linhas gerais, a virada da qualidade traz ao debate elementos que atribuem qualidade aos alimentos que superam conformidades técnicas, mas consideram elementos como cultura, tradição, modo de vida, vínculo com o natural, entre outros (GOODMAN; DUPUIS: GOODMAN, 2012). O "quality turn" é também uma expressão do papel cada vez mais ativo dos consumidores na política de construção de qualidade, "consiste na proliferação de redes alimentares alternativas, trazendo consigo preocupações com a segurança alimentar e a qualidade dos alimentos" (GOODMAN; DUPUIS; GOODMAN, 2012, p. 87).
} 
é global, no local temos de encontrar a liberdade" (DUPUIS; GOODMAN, 2005, p. 361).

Conforme Fonte (2008), há dois modelos de relocalização de alimentos em torno das redes locais de alimentos (local food networks), identificados pela autora com base em estudos de caso em dez países europeus. Um primeiro consiste na perspectiva da "reconexão", que visa reconstruir a relação entre produtores e consumidores. A discussão em torno desse modelo pressupõe que houve uma "ruptura", uma separação, entre a produção de alimentos locais e os consumidores, sendo necessário "costurar" e reconectar o que foi rompido. Essa prática foi fortemente utilizada por multinacionais para inserir os produtos orgânicos em sua cadeia, apropriando-se de um "modo" de produção.

Conforme llbery (2005), um mecanismo-chave para a reconexão, amplamente considerado, é o desenvolvimento e comercialização de produtos alimentares que são, de alguma forma, diferentes daqueles produzidos em massa e prontamente disponíveis nos principais pontos de venda, para que os consumidores possam distingui-los dos demais com base em sua aparência. Assim, podem ser diferenças na qualidade, na localização geográfica, ou na forma de produção.

A segunda perspectiva é denominada de "valorização da origem dos alimentos", que reposiciona a produção local em relação aos seus valores, associando-a com práticas de produção de um território e com a tradição dessa população. Segundo Fonte (2008, p. 202), essa perspectiva está "enraizada em uma tradição pré-industrial que foi marginalizada, mas nunca se tornou completamente extinta". Ou seja, não houve uma ruptura ou o "fim" de um modo de produção em detrimento de outro. Eles permaneceram se reproduzindo com base em conhecimento tradicional mesmo frente ao avanço da industrialização, embora em escalas reduzidas e para públicos consumidores específicos. Da mesma forma, Cruz (2012), em seu estudo sobre a valorização de alimentos tradicionais e artesanais do Queijo Serrano nos Campos de Cima da Serra, no Rio Grande do Sul, ao ouvir diferentes atores envolvidos com essa atividade, evidencia que, paralelamente ao avanço da globalização e da homogeneização do consumo alimentar, permanece coexistindo a produção local tradicional, sendo preservados os hábitos de consumo e produção locais.

Para Fonte (2008), uma das formas de incentivar e garantir os alimentos locais pode ser o registro do produto, certificando sua origem e modo de produção. Contudo, a autora esclarece que essa estratégia pode produzir efeitos negativos quando construída com base no conhecimento científico e por atores não locais, podendo vir a retirar a autenticidade de suas técnicas de produção. A pesquisa da autora está de acordo com os resultados encontrados por Dupuis e Goodman (2005). Para eles, corre-se o risco de criar um contexto favorável às elites locais e de construir territórios protegidos, gerando, consequentemente, desigualdades. Por isso, é fundamental repensar o local não como um movimento "romântico" para a emancipação deste, mas como uma ação coletiva, inclusiva e também reflexiva (DUPUIS; GOODMAN, 2005; FONTE, 2008). Desse modo, a revitalização da origem da comida representa também recuperar o conhecimento tradicional, que representa a expressão do conhecimento local (FONTE, 2008).

Outra abordagem interessante para a análise dos mercados é a terminologia dos nested markets, ou mercados aninhados (POLMAN et al., 2010; PLOEG, 2011; PLOEG; JINGZHONG; SCHNEIDER, 2012). Mercados aninhados podem ser visto como uma forma de governança híbrida: um conceito desenvolvido na Nova Economia Institucional, que os vê como combinações específicas de incentivos de mercado e modalidades de coordenação (POLMAN et al., 2010, p. 296). Em suma, os mercados aninhados consistem de um conjunto específico de transações, envolvendo 
produtores e serviços específicos, entre fornecedores e compradores específicos que obedecem a normas específicas e produzem benefícios específicos (PLOEG, 2011; PLOEG; JINGZHONG; SCHNEIDER, 2012). Esta especificidade socialmente construída define e reproduz o mercado aninhado, consistindo de um conjunto de características que "circundam" esse mercado, formando um ninho (PLOEG, 2011). Conforme o autor, a diferença básica, contudo, é que os grandes mercados de produtos agrícolas e alimentares são, cada vez mais, governados por impérios alimentares. Por outro lado, os mercados emergentes estão inseridos em novas redes sociotécnicas que visam proteger espaços específicos contra o regime imperial. Assim, os mercados aninhados significam limites, embora permeáveis, que delineiam um espaço em que as relações alternativas, tendências, identidades e as transações podem ser construídos (PLOEG; JINGZHONG; SCHNEIDER, 2012).

Entretanto, para Polman et al. (2010), o mercado aninhado vai além da definição de produtos "específicos". Ele dispõe de um arranjo coordenado e conduzido por formas ativas de governança, provenientes dos parceiros e por meio de autoridades operacionais. Ou seja, inclui a participação ativa dos atores sociais envolvidos em fazer os mercados aninhados e organizarem os recursos comuns. O termo "recursos de uso comum", ou common pool resources, faz parte de teoria sobre os recursos comuns desenvolvida por Elinor Ostrom. Tais recursos de uso comum são utilizados por um grupo específico de indivíduos (usuários), que Ostrom denomina de "apropriadores", os quais compartilham "recursos-unidades". Assim, há um conjunto de regras que regulam a gestão e uso dos recursos compartilhados (OSTROM, 2010). Cabe mencionar que Ostrom ganhou o Prêmio Nobel de Economia (Prêmio de Ciências Econômicas em Memória de Alfred Nobel), em 2009, por sua contribuição com sua teoria.

Conforme Polman et al. (2010), é necessário, portanto, um conjunto mais ou menos institucionalizado de regras para governar a gestão e o desenvolvimento dos recursos de uso comum. A exemplo disso, algumas das dimensões a serem compartilhas entre produtores, enquanto possíveis recursos de uso comum, são a preservação da biodiversidade, assegurar a paisagem nativa, reproduzir um modo de produção, manter as características culturais da comunidade, tornar o território atrativo para o turismo, entre tantos outros elementos comuns. Assegurar alguns desses recursos comuns pode ser retribuído em reconhecimento e valorização de seus produtos e do que é desenvolvido naquele local, vindo a delinear os mercados aninhados, relocalizando a produção e reconectando produtor e consumidor, locais ecossistemas e produtos, entre outros (POLMAN et al., 2010). Portanto, os mercados aninhados auxiliam na compreensão dos processos de desenvolvimento rural como "[...] respostas multifacetadas e de múltiplos níveis às falhas de mercado" associadas às dinâmicas dos mercados globais de commodities para a produção agrícola e de alimentos (PLOEG, 2011, p. 137).

A próxima abordagem incorpora muito das contribuições já apresentadas até aqui, em que alguns pontos em comum ficarão evidenciados, tratando-se da Teoria das Convenções, a qual sustenta que os mercados são mantidos por um conjunto de regras baseadas em uma incorporação a objetivos que recebem valorações diferenciadas e estão sujeitos a avaliações constantes, vindo a ter múltiplas formas de coordenação. Para essa teoria, a atividade econômica é socialmente construída e mantida por determinada ação coletiva e individual, levando à construção de um conjunto de regras e convenções que orientam as dinâmicas do mercado. Em essência, pretende romper com as ideias e formas de natureza estáticas, que não contemplam a diversidade de dinâmicas que podem existir nos diferentes tipos de mercado. A exemplo disso, a escolha por um ou outro canal de comercialização não é rígida ou orientada apenas por um objetivo, não sendo possível assegurar que um 
produtor comercialize seu produto pelos mecanismos conhecidos, podendo haver a escolha ou criação de um novo meio de escoar sua produção, o qual não estava "previsto" nos cálculos e lógicas econômicas. Assim, o resultado é uma pluralidade de valores que não são livremente transferíveis de uma instituição para outra, em que "o comportamento não é o mesmo em uma família como no mercado ou em uma associação" (EYMARD-DUVERNAY, 2002, p. 63).

No caso do mercado de ações na bolsa de valores, a compra parte de um interesse do ator e de sua suposição de que ocorra um aumento da valorização do que está sendo adquirido, dados os seus fundamentos, que podem ser particulares ou influenciados por informações ou ações coletivas. Orléan (2005) destaca que, quando ocorre um aumento significativo na compra de determinadas ações, dá-se constituição de relações sociais um fenômeno de influência e de difusão de crenças, denominado como um processo de "imitação". O autor aponta que este consiste em um comportamento perfeitamente racional, que conduz coletivamente, podendo até mesmo vir a gerar situações prejudiciais para os envolvidos, como é o caso de quando ocorrem aumentos excessivos (ORLÉAN, 2005). A questão aqui posta permite observar o papel das convenções na coordenação de ações coletivas, que podem contribuir para explicar as ações locais em mercados de contato direto, e não somente como no caso da bolsa de valores.

Portanto, a constituição de relações sociais se dá mediante referências, convenções de fidelidade, de colaboração, de confiança mútua, entre outras, mas, sobretudo, para além somente da qualidade. Se os atores concordam com uma convenção, isso não significa que compartilhem de outras convenções, o central é entrarem em acordo sobre aquilo que interessa aos envolvidos e que os aproxima. Assim, a análise das convenções, de modo específico, é uma ferramenta apropriada a considerar a diversidade de formas de mercado, não apenas entre organizações, mas dentro de uma organização (BOLTANSKI; THÉVENOT, 1991). Por isso, essa teoria se mostra pertinente para compreender a construção e o funcionamento de mercados agropecuários. A pluralidade de formas de organização e funcionamento nas formas de comercialização permite às convenções o papel de serem "minimamente necessárias como sinais de reconhecimento simbólico de filiação e de autoridade", explicando alguns dos comportamentos dos atores (LAZEGA; FAVEREAU, 2002, p. 4), como nas diferentes formas de mercado e canais de comercialização.

As constatações até aqui apresentadas nos põe diante da evidência de que aspectos econômicos, sociais e culturais compõem os elementos que orientam as trocas, e que distintas abordagens podem ser utilizadas para entendê-las. Portanto, estamos vivendo em uma sociedade em que não há mercados "puros", mas sim uma coexistência destes, até mesmo em formas híbridas. Naturalmente, os mercados dependem de um acordo moral para que existam, ou seja, da existência de valores sociais compartilhados. 


\section{CONSIDERAÇÕES FINAIS}

A elaboração deste artigo teve como principal motivação a busca por um referencial teórico que pudesse contribuir para com a realização de um estudo sobre mercados da pecuária familiar no Rio Grande do Sul. Tendo isso claro e considerando as particularidades do contexto estudado - estudos anteriores que apontavam para a necessidade de olhar os mercados da pecuária por meio de óticas que considerassem aspectos para além do econômico -, indicava para a necessidade do uso de abordagens ou de teorias que permitissem um olhar que abarcasse a interação entre relações sociais, culturais e econômicas, conduzindo as escolhas realizadas nesta de revisão.

Por esse motivo, o leitor poderá concluir, ao fim da leitura do texto, que os esforços foram conduzidos de maneira a apresentar de forma sucinta, mas suficientemente robustas, abordagens que apresentassem contribuições para os estudos dos mercados, levando em consideração contextos em que aspectos culturais poderiam ter protagonismo importante nas relações e comercialização. Com isso, é importante assumir que não houve um aprofundamento sobre as escolas clássicas e neoclássicas da economia, uma vez que há ampla variedade de desdobramentos e correntes. Entretanto, os esforços foram dedicados para compreender melhor abordagens que permitissem levar em consideração as relações sociais, chegando à Teoria das Convenções, após as contribuições que ela própria incorpora das demais escolas.

Diante desse cenário, o intuito da investigação que culminou nessa revisão, compreendia a busca por uma abordagem que não desconsiderasse os elementos puramente econômicos de abordagens de mercados, mas que assegurasse a compreensão de elementos sociais e culturais, sem torná-los unicamente centro do estudo. É importante assumir que não é possível apresentar todas as teorias e as abordagens sobre mercados, muito menos esgotá-las, mas foi possível encontrar um denominador comum, por meio de uma teoria que se mostrou interessante para a análise de contextos complexos, reconhecendo suas dificuldades de operacionalização.

Assim, no conjunto dos estudos rurais, por muito tempo, os mercados foram tratados como algo perverso, criado pela comunidade científica, não necessariamente corroborando com a representação do produtor rural, distante da realidade das formas familiares de produção, que, inicialmente, eram tidas como produtoras de bens para - autoconsumo, com alguns poucos registros de comercialização mercantil. Entretanto, o cenário atual de abertura comercial tornou os mercados ainda mais complexos, uma vez que a produção da matéria-prima, o processamento e a distribuição envolvem um conjunto diverso de etapas e de atores, que, por consequência, transmitem a imagem de um mercado distante.

Os processos interpretativos sobre as formas existentes de relações econômicas passam a sofrer modificações a partir do final da década de 1980, quando intelectuais dão início a uma discussão que objetiva considerar formas de relações que incorporem aspectos, até aquele momento, não reconhecidos pela economia ortodoxa. Não significa, com isso, que as contribuições obtidas até aquele período eram equivocadas ou deixariam de cooperar com as interpretações acerca das relações nos mercados, pelo contrário, o aporte de novos elementos para a compreensão e a análise das relações mercantis passa a contribuir de forma significativa. Nessa trajetória de avanços sobre estudos relacionados aos mercados, a Teoria das Convenções mostra-se interessante ferramenta para análises complexas, na medida em que sua estruturação trás acumulo dos avanços anteriores 
das diferentes escolas, propondo entrelaçar decisões econômicas com aptidões psicossociais e culturais.

Depois de revisão aprofundada que envolveu o resgate de diferentes perspectivas teóricas utilizadas nos estudos sobre mercados, optou-se por utilizar o suporte conceitual e analítico oferecido pela Teoria das Convenções, visto que pode ser um interessante meio para a compreensão de mercados agropecuários. $\mathrm{Na}$ medida em que compreendemos que mercados é resultado das interações entre diversos atores sociais, em que, por meio de interpretações realizadas pelos envolvidos, passam a regular e politizar as transações nesses espaços, mesmo em meio àqueles mercados considerados convencionais e altamente geridos por conglomerados agroindustriais de processamento de alimentos, é a partir disso que teorias como essa emergem, buscando resposta a tais complexidades. Assim, as convenções representam a convergência por trás da ação nos mercados, apontando que há princípios e valorações comuns entre os atores, constituídos por referências em comum que norteiam essas interpretações. Portanto, consiste do conjunto de orientações que estão por trás das escolhas, resultado de interações de atores individuais e coletivos, organizando e regendo ações como acordos construídos gradualmente. Essa teoria fornece elementos para entender os mercados locais, bem como aqueles sem um lugar específico, na medida em que permite verificar a interferência dos mais diversos atores na condução da ação nos mercados.

Portanto, identificar as estratégias dos produtores rurais para se inserir nos diferentes mercados, localizando e descrevendo os espaços de interação e troca de produtos, demonstrando a existência ou não de códigos sociais específicos que determinam, por vezes, a conduta dos indivíduos e do coletivo, representa um importante avanço para os estudos rurais. Com tais informações em mãos, ações e estratégias de desenvolvimento rural podem vir a ser pensadas com o propósito de favorecer cada vez mais a autonomia para os produtores rurais familiares, buscando remuneração adequada e almejando ampliar a possibilidade de espaços de troca de informações, direcionados a contribuir na determinação do canal de comercialização para o escoamento de seus produtos.

Mesmo assim, a Teoria das Convenções tem sua limitação na técnica de investigação empírica, uma vez que é necessária uma imersão na realidade de interesse do estudo, de forma que, em meio às interações entre os diferentes atores, regras que conduzem a constituição das convenções possam ser identificadas. De todo modo, a Teoria das Convenções se mostra útil para estudos que almejam verificar a dinâmica dos processos não apenas de mercados, visto que permite compreender o dinamismo e o movimento dos atores, que podem estar reproduzindo e (re)fortalecendo convenções, como também constituindo novas regras que, posteriormente, podem vir a se tornar convenções.

\section{REFERÊNCIAS}

AKERLOF, G. The Market for "Lemons": Quality Uncertainty and the Market Mechanism. Quarterly Journal of Economics, Oxford, v. 84, n. 3, p. 488-500, Aug. 1970.

APPADURAI, A. A vida social das coisas: as mercadorias sob uma perspectiva cultural. Tradução de Agatha Bacelar. Niterói/RJ: EdUFF, 2008.

BECKERT, J. The social order of markets. Max Planck Institute for the Study of Societies, Discussion Paper 07/15, 2007. 31 p. 
BECKERT, J. The social order of markets. Theory and Society, Cologne, v. 38, n. 3, p. 245-269, Jan. 2009.

BOLTANSKI, L.; THÉVENOT, L. De la justification. Paris: Gallimard, 1991.

COASE, R. H. The Nature of the Firm. Economica, London, v. 4, n. 16, p. 386-405, Nov. 1937.

CONTERATO, M. A. et al. Mercantilização e mercados: a construção da diversidade da agricultura na ruralidade contemporânea. In: SCHNEIDER, Sérgio; GAZOLLA, Marcio. (Org.). Os atores do desenvolvimento rural: perspectivas teóricas e práticas sociais. Porto Alegre: Editora da UFRGS, 2011, p. 67-89. (Série Estudos Rurais)

CORONEL, D. et al. Exportações do complexo brasileiro de soja vantagens comparativas reveladas e orientação regional. Revista de Política Agrícola, Brasília, v. 17 , n. 4 , p. $20-32$, out./nov./dez. 2008.

CRUZ, F. T. Produtores, consumidores e valorização de produtos tradicionais: um estudo sobre qualidade de alimentos a partir do caso do queijo serrano dos Campos de Cima da Serra - RS. 2012. Tese (Doutorado em Desenvolvimento Rural) - Programa de Pós-Graduação em Desenvolvimento Rural, Universidade Federal do Rio Grande do Sul, Porto Alegre, 2012.

DUPUIS, M. E., GOODMAN, D. Should We Go 'Home' to Eat?: toward a reflexive politics of localism. Journal of Rural Studies, New York, v. 21, n. 3, p. 359-371, July 2005.

ELLIS, F. Peasant economics: Farm households and agrarian development. 1. ed. Cambridge: Cambridge University Press, 1988.

EYMARD-DUVERNAY, F. Conventionalist approaches to enterprise. In: FAVEREAU, Olivier; LAZEGA, Emmanuel (Org.). Conventions and Structures in Economic Organization: Markets, Networks and Hierarchies. Cheltenham: Edward Elgar, Paris: University of Paris X, 2002. p. 60-78.

EYMARD-DUVERNAY, F. Conventions de qualité et formes de coordination. Revue Économique, Paris, v. 40, n. 2, p. 329-359, Mars 1989.

FERRARI, D. Cadeias agroalimentares curtas: a construção social de mercados de qualidade pelos agricultores familiares em Santa Catarina. 2011. Tese (Doutorado em Desenvolvimento Rural) - Programa de Pós-Graduação em Desenvolvimento Rural, Universidade Federal do Rio Grande do Sul, Porto Alegre, 2011.

FONTE, M. Knowledge, food and place: a way of producing, a way of knowing. Sociologia Ruralis, Assen (Holanda), v. 48, n. 3, p. 200-222, jul. 2008.

FRANÇOIS, E. P. O ambiente institucional na cadeia produtiva avícola do RS: regulação e desenvolvimento de mercado baseado no status sanitário dos planteis. 2013. Dissertação (Mestrado em Economia) - Programa de Pós-Graduação em Economia, Universidade Federal do Rio Grande do Sul, Porto Alegre, 2013. 
GARCIA-PARPET, M.F. A construção de um mercado perfeito: o caso de Fontainesem-Solange. Estudos Sociedade e Agricultura, Rio de Janeiro, n. 20, p. 5-44. abr. 2003.

GARCIA-PARPET, M. F. Mercados e modos de dominação: a feira e as vinculações de trabalhadores na plantation açucareira nordestina. In: NEVES, Delma Pessanha; MORAES SILVA, Maria Aparecida de Moraes (Org.). Processos de constituição e reprodução do campesinato no Brasil. SP. Ed. UNESP/NEAD, v. 1, 2009. p. 6987.

GOODMAN, D. The quality 'turn' and alternative food practices: reflections and agenda. Journal of Rural Studies, New York, v. 19, n. 1, p. 1-7, Jan. 2003.

GOODMAN, D.; DUPUIS, M. E., GOODMAN, M. K. Alternative food networks: knowledge, practice, and politics. London and New York: O Routlege, 2012.

GRANOVETTER, M. Ação econômica e estrutura social: o problema da imersão. In: MARTES, Ana Cristina Braga (Org.). Redes e sociologia econômica. São Carlos: EdUFSCar, 2009. p. 31-68.

ILBERY, B. et al. Product, process and place an examination of food marketing and labelling schemes in Europe and North America. European Urban and Regional Studies, Harlow (Inglaterra), v. 12, n. 2, p. 116-132, 2005.

LAZEGA, E.; FAVEREAU, O. Introduction. In: FAVEREAU, Olivier; LAZEGA, Emmanuel (Org.). Conventions and Structures in Economic Organization: Markets, Networks and Hierarchies. Reino Unido: Edward Elgar, Paris: University of Paris X, 2002. p. 1-28.

LIE, J. Sociology of markets. Annual Review of Sociology, Calif/US, v. 27, p. 341360, Aug. 1997.

LONG, N. Sociología del desarrollo: una perspectiva centrada en el actor. México: Centro de Investigaciones y Estudos Superiores en Antropologia Social, 2007.

MARSDEN, T. et al. Food Supply Chain Approaches: Exploring their Role in Rural Development. Sociologia Ruralis, Assen, v. 40, n. 4, p. 424-438, Oct. 2000.

MARSDEN, T. Theorising food quality: some key issues in understanding its competitive production and regulation. In: HARVEY, Mark; MCMEEKIN, Andrew; WARDE, Alan. (Ed.). Qualities of food. New York: Palgrave, 2004. p. 129-155.

MARX, K. O Capital: crítica da economia política. 6. ed. Rio de Janeiro: Bertrand Brasil, 1994.

MATTE, A. Vulnerabilidade, capacitações e meios de vida dos pecuaristas de corte da Campanha Meridional e Serra do Sudeste do Rio Grande do Sul. 2013. Dissertação (Mestrado em Desenvolvimento Rural) - Programa de Pós-Graduação em Desenvolvimento Rural, Universidade Federal do Rio Grande do Sul, Porto Alegre, 2013. 
MIZRUCHI, M. S. Análise de redes sociais: avanços recentes e controvérsias atuais. In: MARTES, A. C. B. (Org.). Redes e sociologia econômica. São Carlos: EdUFSCar, 2009. p. 131-159.

NIEDERLE, P. A. Economia das Convenções: subsídios para uma sociologia das instituições econômicas. Ensaios FEE, Porto Alegre, v. 34, n. 2, p. 439-470, dez. 2013.

NIEDERLE, P. A. Mercantilização, estilos de agricultura e estratégias reprodutivas dos agricultores familiares de Salvador das Missões, RS. 2007. Dissertação (Mestrado em Desenvolvimento Rural) - Programa de PósGraduação em Desenvolvimento Rural, Universidade Federal do Rio Grande do Sul, Porto Alegre, 2007.

NORTH, D. Institutions, Institutional Change, and Economic Performance. Cambridge: Cambridge University Press, 1990.

OLIVEIRA, C. A. O. A dinâmica da estrutura da indústria de carne de frango no Brasil. 2011. Dissertação (Mestrado em Agronegócios) - Programa de PósGraduação em Agronegócios, Universidade Federal do Rio Grande do Sul, Porto Alegre, 2011.

ORLÉAN, A. La sociologie économique et la question de l'unité des sciences sociales. In: STEINER, Philippe; SAINT JEAN, Isabelle This. Histoire et méthode de la sociologie économique. Vol. 55, Paris: Presses Universitaires de France, 2005. p. 279-305.

OSTROM, E. Beyond Markets and States: Polycentric Governance of Complex Economic Systems. American Economic Review, Pittsburgh, v. 100, n. 3, p.1-33, Jun. 2010.

OZVEREN, E. Karl Polanyi and Return of the "Primitive" in Institutional Economics. Journal of Economic Issues, California, v. 41, n. 3, Sept. 2007.

PLOEG, J. D. V. El processo de trabajo agricola y la mercantilizacion. In: GUSMAN, Eduardo Sevilla. (Ed.). Ecologia, campesinato y historia. Madri: Piqueta, 1993. p. 163-195.

PLOEG, J. D. V. Trajetórias do desenvolvimento rural: pesquisa comparativa internacional. Sociologias, Porto Alegre, v. 7, n. 27, p. 114-140, mai./ago. 2011. Disponível em: http://www.scielo.br/pdf/soc/v13n27/a06v13n27.pdf. Acesso em: 10 out. 2014.

PLOEG, J. D. V.; JINGZHONG, Y.; SCHNEIDER, S. Rural development through the construction of new, nested, markets: comparative perspectives from China, Brazil and the E.U. Journal of Peasant Studies, London, v. 39, n. 1, p. 37-41, 2012.

POLANYI, K. A grande transformação: as origens da nossa época. Rio de Janeiro: Ed. Campus, 1980. 
POLANYI, K. La economía como actividad institucionalizada. In: POLANYI, Karl; ARENSBERG, Conrad M.; PEARSON, Harry W. (Org.). Comercio y mercado en los impérios antiguos. Barcelona: Labor Universitaria, 1976. p. 289-316.

POLMAN, N. et al., Nested markets with common pool resources in multifunctional agriculture. Rivista di Economia Agraria, Bologna, Italia, n. 2, p. 295-318, Mar. 2010.

ROSSETTI, J. P. Introdução à economia. 8. ed. São Paulo: Atlas, 1980.

SABOURIN, E. Camponeses do Brasil: entre troca mercantil e reciprocidade, Rio de Janeiro: Garamond, 2009.

SABOURIN, E. Práticas sociais, políticas públicas e valores humanos. In: SCHNEIDER, Sergio (Org.). A diversidade da Agricultura Familiar. Porto Alegre: Ed. da UFRGS, 2006. p. 215-239.

SANDEL, M. J. O que o dinheiro não compra: os limites morais do mercado. Tradução de Clóvis Marques. 6. ed. Rio de Janeiro: Civilização Brasileira, 2014. 237p.

SCHERER-WARREN, I. Das mobilizações às redes de movimentos sociais. Sociedade e Estado, Brasília, v. 21, n. 1, p. 109-130, jan./abr. 2006.

SILVA, A. L. G. Concorrência sob condições oligopolísticas: contribuições das análises centradas no grau de atomização/concentração dos mercados. 2. ed. Campinas/SP: Unicamp, 2010. (Coleção Teses). Disponível em: https://www3.eco.unicamp.br/neit/images/stories/arquivos/Teses_Neit/tese_ana_luci a.pdf. Acesso em 20 jan. 2019.

SILVA, D. W. Produzindo prerrogativas de cidadania: o acesso da agricultura familiar à política de fornecimento de produtos para a alimentação escolar. 2015. Tese (Doutorado em Desenvolvimento Rural) - Programa de Pós-Graduação em Desenvolvimento Rural, Universidade Federal do Rio Grande do Sul, Porto Alegre, 2015.

SILVA, L. X. Análise do complexo agroindustrial fumageiro sul-brasileiro sob o enfoque da economia dos custos de transação. 2002. Tese (Doutorado em Economia) - Programa de Pós-Graduação em Economia, Universidade Federal do Rio Grande do Sul, Porto Alegre, 2002.

SOUZA, Â. R. L. Competitividade da cadeia produtiva de arroz beneficiado do Rio Grande do Sul e do Uruguai: um estudo utilizando a matriz de análise de políticas. 201f. 2014. Tese (Doutorado em Agronegócios) - Programa de Pós-Graduação em Agronegócios, Universidade Federal do Rio Grande do Sul, Porto Alegre, 2014.

STEINBERG, M. Padrões de concorrência no Mercado Brasileiro de Torrefação e Moagem de Café e 1997-2005. 2006. Dissertação (Mestrado em Administração) Programa de Pós-Graduação em Administração de Empresas, Fundação Getúlio Vargas, Rio de Janeiro, 2006.

THÉVENOT, L. Equilibre et rationalité dans un univers complexe. Revue Économique, numéro spécial L'économie des conventions, Paris, v. 40, n.2, p. 147-197, Mars 1989. 
THÉVENOT, L. Organized Complexity: Conventions of Coordination and the Composition of Economic Arrangements. European Journal of Social Theory, London, v. 4, n. 4, p. 405-425, Nov. 2001.

WILKINSON, J. Mercados, redes e valores. Porto Alegre: Ed. UFRGS, 2008.

WILLIAMSON, O. E. Comparative Economic Organization: The Analysis of Discrete Structural Alternatives. Admnistrative Science Quartertly, New York, v. 36, p.269296, June 1991.

WILLIAMSON, O. E. Mercados y Hierarquias: su análisis y sus implicaciones antitrust. México: Fondo de Cultura, 1991.

WILLIAMSON, O. E. The economic institutions of capitalism: firms, markets, relational contracting. New York: The Free Press, 1985.

WILLIAMSON, O. E. Transaction Cost Economics and Organization Theory. Journal of Industrial and Corporate Change, Oxford, v. 2, n. 2, p. 107-156, 1993.

ZYLBERSZTAJN, D. Estruturas de governança e coordenação do agribusiness: uma aplicação da nova economia das instituições. 1995. Tese (Livre Docência) Departamento de Administração da USP, Universidade de São Paulo, São Paulo, 1995. 